\title{
Levantamento do uso de técnicas criativas na indústria criativa de Criciúma/SC
}

\author{
Survey of the use of creative techniques in the creative industry of Criciúma / SC
}

SANGALETTI, Rhangel; Bacharel; Faculdade Satc

rhangel.s@gmail.com

DENARDI, Davi Frederico do Amaral; Mestre; Faculdade Satc

denardi.davi@gmail.com

\section{Resumo}

Atualmente, graças à pressão dos mercados e à globalização muito se tem discutido sobre criatividade e inovação, porém, não fica claro em que profundidade esses conceitos são aplicados no dia a dia da indústria criativa. Assim, o presente estudo tem como objetivo levantar por meio de entrevistas os processos criativos aplicados em empresas do ramo criativo de Criciúma/SC. Os resultados sugerem que graças à pressão do tempo e a falta de conhecimento aprofundado sobre o tema as empresas se utilizam de apenas poucas ferramentas criativas e não apresentam grande inovação em seus processos de forma geral.

Palavras Chave: criatividade; inovação; processo criativo.

\begin{abstract}
Today, thanks to market pressure and globalization, much has been discussed about creativity and innovation, however, it is not clear to what depth these concepts are applied in the dayto-day creative industry. Thus, the present study has as objective to raise through interviews the creative processes applied in companies of the creative branch of Criciuma / SC. The results suggest that thanks to the pressure of time and lack of in-depth knowledge on the subject, companies use only a few creative tools and do not present great innovation in their processes in general.
\end{abstract}

Keywords: Creativity; innovation; creative process. .

\section{Introdução}

Devido à globalização e às constantes modificações sociais, as tecnologias e objetos passam por uma renovação constante. Com isso mudam também, as necessidades da sociedade, e, buscando suprir essa demanda, os produtos sofrem alterações frequentes em suas características.)

Neste cenário de mudanças contínuas, produtos normalmente tornam-se obsoletos com um mês de uso. Assim, é preciso que as empresas criem novas funcionalidades para seus atuais produtos a fim de atender à demanda incessante por inovação. Apenas realizar upgrades 
já não é mais o suficiente, eles devem, a cada lançamento, receber uma nova funcionalidade e que esta seja desejada pelos consumidores e, para isso, implantam-se inovações.

Assim, deve-se definir o termo inovação que é entendido como algo que é novo, uma novidade. Percebe-se assim que está muito relacionada à criatividade, pois para que se alcancem novos resultados ou novas soluções, é preciso pensar de uma maneira diferente da concorrência, ou até da própria empresa. Faz-se então necessário que empresas busquem profissionais treinados e com capacitação para tais mudanças, e que a cada dia se busquem ideias inovadoras.

Neste cenário, espera-se, de maneira generalizada, que designers sejam profissionais criativos e inovadores por natureza, profissionais que estejam engajados em uma busca constante por mudanças, buscas por novas funcionalidades para produtos ou soluções para problemas existentes.

Em meio a essas necessidades, o designer precisa encontrar meios de gerar essas novas relações, ou seja, buscar maneiras para estimular a criatividade. Em vista disso, o objetivo deste trabalho é de levantar os processos em empresas do ramo criativo - agências de publicidade ou de design por exemplo - a fim de identificar práticas recorrentes ou inovadoras.

\section{Criatividade e Design}

Quando se ouve a palavra Design, logo as pessoas se lembram de artes, produtos inovadores, o inédito. Porém, poucas são as que pensam na criatividade como um potencial a ser treinado. Isso se dá pelo fato de, por muito tempo, a criatividade ser tratada como um dom, uma dádiva advinda dos deuses para seres iluminados. Bahia (2007), para explicar esta crença, cita Kraube (2000), que reforça que apenas em 1304, quando Giotto executou o afresco "A Deposição de Cristo" e a assinou, ele desafiou uma regra religiosa, que pregava que o autor não poderia assinar suas obras, pois o ser criativo possuidor da capacidade criativa era Deus.

Contudo, atualmente, já se tem a criatividade como um potencial humano, como citam os autores Mano e Zagalo:

Um primeiro contexto apresenta-nos a criatividade com um caráter mágico e religioso, empregador de atributos divinos. Já o segundo contexto, o econômico, apresenta-nos a criatividade como uma atividade produtiva, que podemos explicá-la e induzi-la. (MANO e ZAGALO, 2009, p. 1214)

Neste trabalho, será entendida a criatividade em seu segundo contexto.

Faz-se necessário abordar o conceito de criatividade que, para Mano e Zagalo (2009), tem como principal foco a solução de problemas. Os autores definem a origem dessas soluções como a capacidade do ser humano em fazer relações de experiências antes não relacionadas, dando início a um novo esquema mental de onde surgirão novas experiências, ideias e processos.

Essas experiências são extremamente únicas, pois estão dentro de cada ser, onde cada um percebe as coisas de acordo com sua própria identidade, sua maneira de ver o mundo, ou seja, sua cultura.

Assim, pode-se ter o designer - tratando-se aqui dos profissionais das mais variadas vertentes do design - como um profissional criativo.

A natureza criativa do homem é gerada pelo seu contexto cultural, e suas necessidades e 
seus valores culturais moldam seus valores de vida. Assim, a criatividade está relacionada à cultura de duas maneiras: a primeira como característica individual, o potencial criativo; e a segunda como criação, que é o uso dessas potencialidades para criar de acordo com as necessidades de determinada cultura. (Ostrower, 1987, p. 5)

Neste contexto, em que para Ostrower (1987) a criatividade relaciona-se à criação, Robinson (2011) diz que não se pode pensar em criatividade sem pensar na imaginação, que esta é a fonte daquela. Define que imaginação é a capacidade de trazer elementos ou objetos à mente, pode-se criar imagens que sejam existentes no mundo real ou não. E a criatividade está relacionada a "fazer", e que ser criativo exige criar soluções, objetos, etc., pois essa qualificação exige produzir algo de forma intencional.

Baseando-se nos autores, pode-se afirmar que se consegue desenvolver um potencial criativo, tendo em vista que a criatividade não surge em um momento repentino - a ideia em si até pode surgir - porém, elas serão geradas por meio de toda a vivência, cultura e memória de um ser, esta última sendo junto com a imaginação os pontos chave para o potencial criativo.

A partir de então, em que já se definiu a criatividade como uma qualidade a ser aperfeiçoada e não um dom, Robinson (2011) divide a criatividade em duas categorias: a) a criatividade geral, que é quando se consegue buscar soluções originais para os problemas diários - o que se torna possível, pois, como visto, a criatividade acontece a partir de experiências pessoais; b) a criatividade pessoal, que se baseia em suas paixões e talentos pessoais, uma área de conhecimento mais desenvolvida ou algum apreço por algo, o fato de entender mais sobre determinado assunto pode tornar uma pessoa mais criativa que outra.

Com base nos conceitos de criatividade citados acima, pode-se definir o designer como um profissional criativo, pois busca solucionar problemas por meio de novas utilidades e/ou características para determinados produtos - dentro das mais variadas áreas de atuação - e, para isso, cria novas conexões cognitivas, obtendo novos resultados.

Neste contexto, pode-se convergir as definições citadas e conclui-se que a criatividade se encontra dentro da cultura de duas maneiras: a) a primeira como característica de determinado ser, onde cada um possui cultura própria e desenvolve novas soluções por meio de ligações entre experiências ante vividas; b) e a segunda como um produto ou solução que é desenvolvida para atender às necessidades de uma sociedade.

\section{Inovação}

Abordados os conceitos de criatividade e suas relações com a cultura, imaginação e memória de cada ser e também explicados os processos criativos e fatores que o influenciam, neste item, será abordado o tema inovação aplicada a meios empresariais.

Segundo Serafim (2011), a inovação pode ser tratada de duas maneiras distintas dentro do meio empresarial: como estratégia da empresa ou como cultura, esta sendo o foco deste estudo.

O autor ainda afirma em relação a essa cultura que é criada e dirigida por um sistema de princípios e práticas visando a encorajar a combinação de criatividade e tecnologia, buscando satisfazer as necessidades dos clientes. E, para cria-la, a empresa deve aceitar a inovação como centro do negócio, pois pode levar muitos anos para que seja notado resultado. Explica também que a inovação não está relacionada somente a produtos e processos, mas que, acima de tudo, a pessoas, que utilizam sua imaginação e comprometem-se com um ideal.

Scherer e Carlomagno (2009) corroboram com o autor afirmando que para inovar e encorajar a combinação de criatividade e tecnologia, é preciso tolerar erros e assumir riscos, 
onde, ao se adotar uma cultura de inovação em uma empresa, implementa-se uma maneira de trabalho que busca soluções criativas, acarretando em inúmeras tentativas e erros. E também que investir em pesquisa e desenvolvimento nem sempre resulta em ganhos. Então, para que se possa inovar, é preciso extinguir com a aversão ao risco.

Os autores ainda concordam que inovar, por buscar desenvolver novos processos ou produtos, pode levar meses e até anos, tornando-se assim um investimento de médio a longo prazo para empresas.

Ao aprofundar-se ao tema já não se pode mais utilizar a definição de inovação conforme citada na introdução deste trabalho - baseando-se em um significado superficial da palavra. Como explica Serafim (2011), no mundo corporativo muitas pessoas atribuem esse significado à inovação e acreditam que inovação, criatividade e invenção são a mesma coisa. $\mathrm{O}$ autor divide-os com conceitos distintos, ainda que acredite que estejam profundamente interligados.

O autor, ao tratar os três conceitos de maneira distintas, afirma que a inovação, neste contexto, é o objetivo final, que resulta da introdução de algum elemento novo que seja capaz de criar valor econômico; a criatividade é o ponto de partida para a inovação; a invenção será citada posteriormente.

Corroborando com o autor, Robinson (2011) explica que uma cultura de inovação depende do estímulo de três processos inter-relacionados. O primeiro é a imaginação, o segundo é a criatividade e, por último, e como resultado, a inovação.

Como se pode perceber, os autores tratam a inovação como objeto final de todo o processo interno. Robinson afirma ainda que a inovação pode estar presente em todos os aspectos de funcionamento de uma empresa, não somente nos produtos finais, ou seja, uma empresa pode ser inovadora em seus processos ou sistemas de produção por exemplo.

Abordando agora o conceito de inovação, quando tratada como um aspecto de um produto final, pode-se diferenciar inovação de invenção. Scherer e Carlomagno (2009) afirmam que inovar leva a resultados, e que não significa inventar, quando simplesmente se geram novos conceitos, mas não os incorporam a nenhum produto, não existe inovação.

O autor define então que para caracterizar-se como inovação, uma invenção precisa ser viável, ter aceitação pelo mercado e assim gerar retorno para as partes envolvidas.

\section{Técnicas criativas}

Com o crescente aumento de informações transmitidas, e a busca cada vez maior de se atingir resultados e encontrar soluções o mais breve possível, passou-se a desenvolver técnicas que possuem como objetivo estimular as realizações de ligações entre experiências ou memórias, ou seja, estimular a criatividade.

Em relação às técnicas, Alves et alli $(2007$, p. 1) definem-as como "formas heurísticas de acelerar o processo criativo". Os autores afirmam ainda que elas ao unificar a criatividade da equipe, deixam o projeto menos necessitado de pessoas com a criatividade natural.

Ainda se tratando da utilidade dessas técnicas, Alves et al (2007) explicam que elas buscam gerar soluções criativas a qualquer momento, diminuindo a dependência de insights.

Buscando aumentar o potencial criativo pode-se utilizar o brainstorming, que segundo Baxter (2000) baseia-se no princípio de que "quanto mais ideia melhor". Em relação a execução, afirma que o grupo é formado por seis pessoas, sendo que um é líder e os demais são membros regulares. Onde o líder é o responsável por orientar o grupo, e definir o problema. 
Cabe ressaltar que o autor afirma que a qualidade de ideias depende da preparação dos participantes, ou seja, do seu conhecimento com o problema, e o ideal é ter sempre duas pessoas ou mais que estejam familiarizadas com o mesmo. Serão geradas mais ideias se na fase de ideação não houver nenhum tipo de avaliação. E que também é necessário que seja disponibilizado tempo para que a sessão aconteça, de trinta minutos a duas horas.

Também com a mesma finalidade têm-se o painel semântico, que Mello (2011) define como uma busca de imagens ou características que simbolizam aspectos desejados para o objeto. Pode-se citar como exemplo um case fictício criado pelo autor onde duas características do produto são: leve e ágil; e o público para este produto são praticantes de esportes. Será necessário então criar três painéis, um representando cada uma das características e outro representando o público e seu estilo de vida.

E por último, o painel de referência, este em pesquisa posterior às entrevistas, acabou não sendo definido como técnica criativa, por não ser citado por nenhum autor. Porém, baseando-se nas informações obtidas, o painel de referência acaba sendo inserido dentro do painel semântico, mas com foco um divergente do citado. No painel de referência, a pessoa abordará não as características diretas do produto a ser desenvolvido, mas sim, referências de semelhantes ao produto desejado.

Ainda buscando aumentar o potencial criativo, pode-se utilizar da cocriação que é uma ferramenta que busca estimular a criatividade. Para Franco (2012) cocriação é um processo que tem como objetivo criar ou desenvolver ideias conjuntamente. Ou seja, é um grupo de pessoas que busca soluções para um problema em conjunto.

Já Mecheln et alli (2012), abordam um outro contexto de cocriação, em que empresas se utilizam dos próprios clientes para solucionar dúvidas em relação à produção de novos materiais e/ou serviços.

Outra prática inovadora pode ser considerada o Design Sprint do Google, a empresa define a prática como uma estrutura para equipes de tamanhos variados, que tem como finalidade testar e resolver problemas de design no período de dois à cinco dias. A proposta é de que tanto o design quanto a agilidade são importantes, onde criou-se os sprints de design, que seriam corridas do design em tradução livre, que na prática buscam testes e prototipagens rápidos. É uma pratica melhor para UX ou Design Thinking, por exemplo, mas que podem adaptar-se a equipes que estejam apenas praticando design. A ideia do design sprint surgiu de uma adaptação do design thin-king.

Também identificado como prática inovadora, o Método do Diamante Duplo, desenvolvido pelo Design Council em 2005, Design Council (2007) divide o processo em quatro fases são elas Descobrir, Definir, Desenvolver e Entregar. Assim como o design sprint, essa prática se enquadra na caracterização de método e também se utiliza, em algumas de suas etapas, técnicas criativas para geração de ideias. Como é o caso das etapas "descobrir" e "definir", sendo que na primeira a geração é voltada a ideias de maneira geral. Como exemplo de técnica aplicada nesta etapa pode-se citar o brainstorming. E a segunda as técnicas são aplicadas buscando ideias de cunho específico, pode-se citar como exemplo o painel semântico.

Ao longo do capítulo dois, foi abordada a criatividade no seu contexto cognitivo, em que pode ser aplicado de duas maneiras: dentro da cultura individual e da cultura social. Sendo que a cultura individual é utilizada para desenvolver o projeto para atender necessidades da cultura social.

Estudou-se também sobre inovação que, para Robinson (2011), é a criatividade aplicada 
à solução de problemas ou geração de novos produtos. Também foram vistas maneiras de implantar ou potencializar a cultura de inovação em uma empresa, bem como técnicas que servem como métricas da inovação.

E, por último, buscou-se maneiras de estimular a criatividade, por meio de técnicas criativas, e métodos de trabalho que forneçam liberdade para o desenvolvimento e expressão do potencial criativo.

\section{Procedimentos metodológicos}

A fim de levantar os processos relacionados à criatividade em empresas do ramo criativo no presente estudo foram realizadas entrevistas com 13 colaboradores do setor criativo de Criciúma/SC. Sendo uma pesquisa exploratória o uso da entrevista se dá para que se tenha um primeiro contato com o problema na criatividade na cidadã.

Desenvolveu-se então um roteiro de entrevistas, que para Gil (2008) deve conter questões claras, para que os entrevistados compreendam com facilidade, e que elas não devem exigir auxílio do entrevistador para serem compreendidas. Estas são descritas abaixo sendo correlacionadas com a fundamentação teórica.

1) Qual seu nome, sexo, idade, formação, cargo ocupado na empresa e tempo de experiência no setor?

2) Em nível pessoal, qual a importância da criatividade em sua vida particular e na função que você exerce em seu local de trabalho?

3) Como é o processo de criação utilizado em seu meio profissional para o desenvolvimento de projetos? Ex. Desenvolvimento de uma marca.

a. Na fase de geração de ideias que você citou, quais são as técnicas utilizadas para alcançar o objetivo proposto?

b. Por que são utilizadas essas técnicas e não outras?

4) Para você o que é inovação?

a. Você considera a sua empresa inovadora?

b. De que forma ela busca a inovação?

Essa questão tem como objetivo identificar o conhecimento do entrevistado sobre inovação, visando inserir a citação dentro do contexto abordado por Serafin (2011) e Robinson (2011), se a empresa incentiva tais práticas, e, caso incentive, onde se insere dentro dos tipos abordados na Tab. 1.

As entrevistas ocorreram no período de 03 à 11 de Outubro, e foram entrevistados 13 pessoas. Os entrevistados estavam cursando Design Gráfico (DG) ou Publicidade e Propaganda (Publicidade e Propaganda), e que esteavam trabalhando em empresas do ramo criativo - agências de publicidade, escritórios de design ou em setores de criação em empresas de outros ramos.

Foram entrevistados 6 acadêmicos de Publicidade e Propaganda que atualmente trabalham em agências de publicidade, dos quais 3 eram do sexo masculino e 3 do sexo feminino com idades entre 19 e 23 anos, os entrevistados oito, nove e onze trabalhavam com criação, a Entrevistada 10 era estagiária em pesquisa científica, a Entrevistada 12 exercia a função de analista de marketing e o Entrevistado 13 de analista de mídias sociais. E 7 acadêmicos de Design Gráfico que atuam no ramo, dos quais eram 4 do sexo feminino e 3 do sexo masculino, com idades entre 21 e 24 anos, os entrevistados um, dois, três, cinco e sete exerciam a função de designer, as entrevistadas quatro e seis eram diretoras de arte. A quantidade de entrevistados foi estabelecida de acordo com o cálculo de mínimo de 
entrevistados e de saturação de resultados estabelecido por Thiry-Cherques (2009) que é entre 6 a 12 pessoas.

A seguir serão expostas, analisadas e discutidas as respostar obtidas por meio das entrevistas realizadas. A análise das respostas, por ser uma pesquisa de origem qualitativa, foram feitas de maneira subjetiva, ou seja, onde não se buscava quantificar o conhecimento de cada entrevistado em relação ao assunto.

\section{Resultados}

Neste capitulo serão analisados os resultados obtidos com as entrevistas realizadas. Para uma melhor organização e entendimento, eles não serão divididos por curso, porém, analisados questão por questão. Os entrevistados com numeração de um a sete são os acadêmicos de design gráfico, e os numerados de oito a treze, de publicidade e propaganda.

Gráfico 1- Em nível pessoal, qual a importância da criatividade em sua vida particular e na função que você exerce em seu local de trabalho?

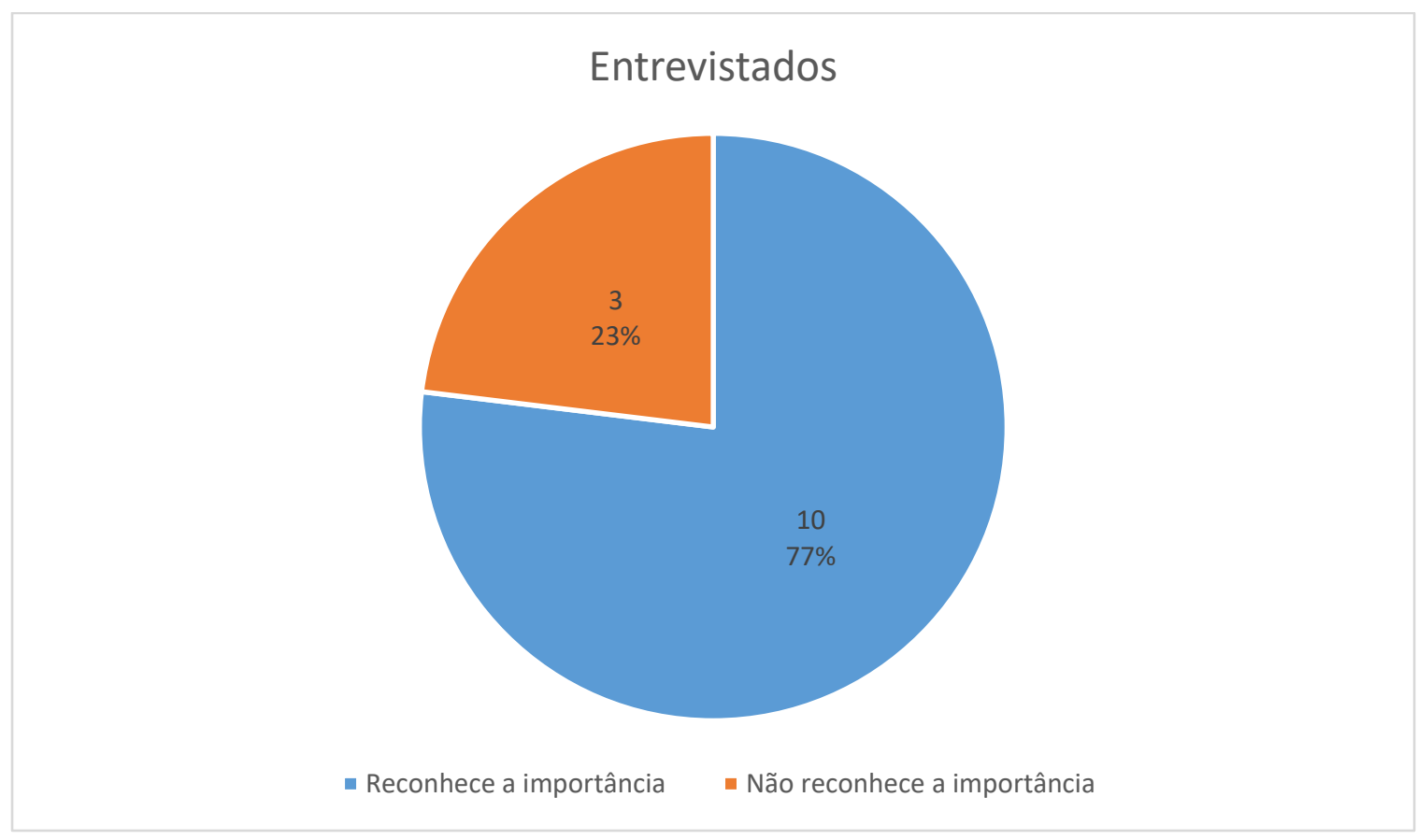

Fonte: dos autores

A questão de número dois (Gráfico 1) da entrevista tinha como objetivo identificar a percepção da importância da criatividade para o entrevistado.

Dos treze entrevistados, dez perceberam de acordo com a pesquisa deste trabalho, afirmando que acreditavam que a criatividade seria importante por sua função de solucionar problemas, corroborando com os autores Mano e Zagalo (2009). Os mesmos dez acreditam que ela possui importância em seus respectivos trabalhos, pois todos precisam buscar soluções criativas diariamente, cada um em sua área de atuação. Dos dez entrevistados citados acima, cinco eram do Design Gráfico e os demais de Publicidade e Propaganda.

Em contrapartida, três abordaram conceitos divergentes dos citados acima. Destaca-se nesse caso a afirmativa da Entrevistada 3, que acredita que a criatividade é uma ferramenta, e 6o GAMPI Plural, 2017, Joinville, SC. 
que é importante pois algo criativo chama à atenção, e acredita que é importante em seu trabalho para criar "coisas" que tenham relação com seu público-alvo. Pode-se perceber que a entrevistada em questão soluciona problemas através da criatividade, porém não ela não faz ligação direta entre a criatividade e a solução de problemas. Esta foi a única entrevistada que citou que a criatividade é algo a ser estimulada, concordando com o Robinson (2011) e Ostrower (1987).

A Entrevistada 4 percebe a criatividade presente em sua vida ao aplicar visões poéticas em cenas de seu cotidiano com pensamento voltado à fotografia. E afirma que a aplica em seu trabalho desenvolvendo materiais gráficos que lhes são solicitados. Assim como a Entrevistada 3, ela soluciona problemas por meio da criatividade - desenvolvendo materiais gráficos para empresas - porém não a associou à solução de problemas.

O Entrevistado 8 não mencionou a importância da criatividade, citou apenas que para ser criativo é preciso ser uma "pessoa aberta". E, juntamente com o Entrevistado 1, abordou o contexto citado por Ostrower (1987) fazendo relação da mesma com sua cultura e com suas experiências.

A terceira questão tinha como foco levantar o processo de criação de cada entrevistado, buscando identificar as técnicas criativas utilizadas na etapa de geração de ideias, e caso este processo exista, e também se existe algum processo inovador.

Quadro 1 - Resultados da questão três: Como é o processo de criação utilizado em seu meio profissional para o desenvolvimento de projetos?

\begin{tabular}{lc} 
Ferramenta & Frequência \\
\hline Painel de Referência & 10 \\
Brainstorming & 4 \\
Painel Semântico ou Mood Board & 2 \\
\hline Total & 16
\end{tabular}

Fonte: do autor

Foi percebido que os treze entrevistados possuíam processos de criação, onde apenas oito utilizavam-se de técnicas criativas para gerar ideias. Das técnicas, o painel de referência foi citado oito vezes, sendo que destes oito, cinco utilizavam a técnica individualmente em seu dia a dia sempre que necessitavam desenvolver algo. Dois aplicavam a técnica com a equipe de trabalho. E apenas o Entrevistado 2 não a utilizava diariamente, pois as técnicas em sua empresa são aplicadas periodicamente para geração de framerwoks (padrões visuais), e que não aplica nenhuma técnica criativa em suas funções diárias.

Os entrevistados de Publicidade e Propaganda 8, 9, 12 e 13, apenas realizam a pesquisa das referências e não criam painéis. A Entrevistada 12 afirma que cria os painéis somente quando o trabalho é maior, segundo ela na realização de lookbooks.

O brainstorming apareceu quatro vezes, e são feitos para definição de conceitos maiores, assim são utilizados previamente aos painéis de referência. Sendo que apenas a Entrevistada 03 o aplica individualmente.

O painel semântico foi citado três vezes, em uma delas a Entrevistada 7 usa a terminologia mood board. Ambos aplicam junto de toda a equipe. 
A Entrevistada 4 trabalha com direção de arte há três anos e afirmou que em seu local de trabalho não são aplicadas técnicas criativas, e o entrevistador não conseguiu identificar nenhuma ao longo da entrevista.

A Entrevistada 10 é estagiária em pesquisa científica há nove meses, e cita como técnicas criativas utilizadas o desenvolvimento de personas, a criação de um modelo de briefing, estas quando trabalhava com gerenciamento de página de mídia social, e a comunicação guarda-chuva em sua atual pesquisa. E justifica a utilização desta última para comunicar várias pessoas com um custo reduzido. A técnica de comunicação guarda-chuva, não se aplica como inovadora pois a autora cita como algo muito utilizado quando se tem como objetivo reduzir custos, porém reduz-se também a eficiência. E acabam sendo caracterizadas mais como método de abordagem do público do que técnicas criativas.

$\mathrm{Na}$ segunda questão de apoio não se conseguiu atingir o objetivo da mesma, que era o de identificar se o entrevistado possuía conhecimento ou não da ligação de criatividade com a cultura, memória e vivência, onde nenhum deles conseguiu exemplificar o porquê que são utilizadas as técnicas citadas. Pelo fato de as respostas serem consideravelmente divergentes, não foi possível agrupá-las.

Quadro 2 - Resultados da questão três: Como é o processo de criação utilizado em seu meio profissional para o desenvolvimento de projetos?

\begin{tabular}{|c|c|c|c|}
\hline \# & Experiência & Ferramenta & Justificativa para o uso \\
\hline 1 & Menos de 2 anos & $\begin{array}{l}\text { Painel de } \\
\text { referência }\end{array}$ & Não soube justificar \\
\hline 2 & Menos de 2 anos & $\begin{array}{l}\text { Brainstorming e } \\
\text { painel de } \\
\text { referência }\end{array}$ & $\begin{array}{l}\text { Para gerar ideias "aleatórias" e soluções } \\
\text { interessantes }\end{array}$ \\
\hline 3 & Menos de 2 anos & Brainstorming & Faz parte da cultura da empresa \\
\hline 4 & Menos de 2 anos & $\begin{array}{l}\text { Painel de } \\
\text { referência }\end{array}$ & Está acostumado com a técnica \\
\hline 5 & Menos de 2 anos & $\begin{array}{l}\text { Painel de } \\
\text { referência }\end{array}$ & Por falta de tempo \\
\hline 6 & Menos de 2 anos & $\begin{array}{l}\text { Painel de } \\
\text { referência }\end{array}$ & Não soube justificar \\
\hline 7 & Menos de 2 anos & $\begin{array}{l}\text { Painel de } \\
\text { referência }\end{array}$ & Não soube justificar \\
\hline 8 & Menos de 2 anos & $\begin{array}{l}\text { Brainstorming e } \\
\text { painel de } \\
\text { referência }\end{array}$ & São técnicas dinâmicas e estimulam a criatividade \\
\hline 9 & Menos de 2 anos & Painel Semântico & A moda trabalha muito com referências visuais \\
\hline 10 & Menos de 2 anos & $\begin{array}{l}\text { Painel de } \\
\text { referência }\end{array}$ & $\begin{array}{l}\text { Ajudam a agilizar a criação, principalmente para } \\
\text { mídias sociais }\end{array}$ \\
\hline 11 & 2 anos & Painel de & Usa por falta de tempo e porque a empresa o \\
\hline
\end{tabular}


referência orienta a seguir tendências

122 anos

Brainstorming e

painel de

referência

133 anos
Painel Semântico
Acredita que ambas as técnicas conseguem um resultado mais assertivo e valoriza o processo junto aos clientes

Utilizado para definirem temas, usa porque foi recomendado por palestrantes do ramo

Fonte: dos autores

A quarta e última questão tinha como objetivo identificar o conhecimento do entrevistado sobre inovação, se a empresa incentiva tais práticas, e, caso incentive, onde se insere dentro do processo da empresa.

Pôde-se observar ao longo das entrevistas que todos os entrevistados utilizavam de sua criatividade para a resolução de problemas, porém alguns não atribuíam essa característica de maneira consciente. Apenas dois entrevistados relacionaram a criatividade de alguma forma ao contexto citado por Ostrower (1987) e Robinson (2011), sendo essa o resultado da cultura, memória e vivências de um ser, nenhum dos entrevistados associou as técnicas criativas como estímulos ao referido contexto.

Quanto à inovação, percebe-se que todos os entrevistados possuem algum entendimento sobre o termo inovação, porém nenhum deles associou a prática à retornos financeiros para a empresa. E em relação ao ambiente de trabalho, as práticas citadas não eram necessariamente inovadoras, como exemplo pode-se citar o caso de cinco entrevistados que acreditam que a inovação está na liberdade dos colaboradores. Apenas um entrevistado descreveu práticas citadas como inovadoras conforme a fundamentação deste trabalho.

\section{Conclusão}

A realização dessa pesquisa teve como objetivo o levantamento dos processos de criação das empresas do ramo criativo na região de Criciúma - SC, a fim de identificar as técnicas criativas ou práticas utilizadas pelos profissionais de design gráfico e publicidade e propaganda no mercado de trabalho.

Abordou-se a criatividade como um potencial humano, e não um dom de poucos, dentro dessa abordagem foi tratada a criatividade como algo que vem da cultura e ao mesmo tempo a serve; onde ela surge como característica de uma pessoa, que tem cultura própria, e através disso desenvolve soluções ou produtos que sirvam para atender a necessidade de uma sociedade, que é parte da cultura social que o mesmo está inserido.

A inovação foi abordada em uma aplicação à meios empresariais, onde foi tratada como uma cultura empresarial. Onde a definição obtida distingue inovação, criatividade e invenção. Sendo a criatividade uma ferramenta para se ter novas invenções, e que a inovação só surge quando essas invenções trazem retornos financeiros.

De acordo com as informações obtidas com as entrevistas, as técnicas recorrentes utilizadas foram, por ordem de citações, o painel de referência, o brainstorming e o painel semântico.

Pôde-se observar que os profissionais de Publicidade e Propaganda, não utilizavam as técnicas criativas frequentemente, sendo que cinco dos seis entrevistados apenas pesquisavam referências e não criavam painéis, e um destes aplicava-as apenas em projetos maiores como 
lookbooks.

Observou-se também que os profissionais não fizeram relação da utilização das técnicas com as características da criatividade, ainda que na maioria dos casos eles tivessem algum entendimento sobre o assunto. A justificativa que mais foi citada foi a falta de tempo para o desenvolvimento dos projetos.

Através das entrevistas se pôde notar que maior parte das empresas citadas, em seu dia a dia trabalham com pequenos projetos que exigem resultados em um período curto de tempo, não foi possível levantar se o prazo é curto devido à falta de planejamento da empresa ou do cliente que solicita o trabalho.

Com base nos levantamentos feitos nessa pesquisa, tornam-se importantes estudos sobre novas formas de trabalho que possam estimular a criatividade, métodos e jornadas de trabalho mais maleáveis por exemplo, ou como abordado, o modelo de equipe cocriativa.

Tornam-se interessantes estudos mais aprofundados às empresas do ramo, buscando identificar pontos onde se pode ampliar o tempo de desenvolvimento, a fim de obter resultados melhores e mais exclusivos.

\section{REFERÊNCIAS}

ALVES, Hobedes de A; CAMPOS, Fabio; NEVES, André. Apli-cação da técnica criativa "Brainstorming Clássico" na ge-ração de alternativas na criação de games. UFPE, 2007.

BAXTER, Mike R. Projeto de produto: guia prático para o design de novos produtos. 2 ed. São Paulo: BLucher, 2000. ISBN 9788521202655

BAHIA, Sara (2007). Psicologia da Criatividade. Manual de Apoio para a disciplina de Psicologia da Criatividade. Mestrado em Teatro e Comunidade da ESTC/IPL

FRANCO, Augusto de. Cocriação: reinventando o conceito. São Paulo, Escola de Redes, $2^{\mathrm{a}}$ edição, 2012. 86p.

GIL, Antonio C. Como elaborar projetos de pesquisa. 4 ed. São Paulo, Atlas, 2002. ISBN 8522431698

MANO, Vinícius; ZAGALO, Nelson. Criatividade: sujeito, processo e produto. $8^{\circ}$ LUSOCOM. Portugal, 2009.

MELLO, Willyams B. de. Proposta de um método aberto de projeto de produto - três alternativas de criação. São Paulo, 2011.

OSTROWER, Fayga; Criatividade e Processos de Criação. Petrópolis: Editora Vozes, 1987.

ROBINSON, Ken. Libertando o poder criativo: a chave para o crescimento pessoal e das organizações. São Paulo (SP): HSM, 2012. 297 p. ISBN 9788565482158.

SCHERER, Felipe Ost; CARLOMAGNO, Maximiliano S. Gestão da Inovação na Prática: 6o GAMPI Plural, 2017, Joinville, SC. 
Como Aplicar Conceitos e Ferramentas para Alavancar a Inovação. São Paulo, Atlas S/A, Livro Digital, 2009.

SERAFIM, Luiz E. O Poder da Inovação - A Experiência da 3M e de Outras Empresas Inovadoras. Editora Saraiva, Versão Digital, 2011.

THIRY-CHERQUES, Hermano R. Saturação em pesquisa qualitativa: Estimativa empírica de dimensionamento. Revista PMKT 03. 2009, p.27 